\title{
Freeform Optics: current challenges for future serial production
}

\section{Schindler, T. Köhler, E. Roth}

C. Schindler, T. Köhler, E. Roth, "Freeform Optics: current challenges for future serial production," Proc. SPIE 10448, Optifab 2017, 1044802 (16 October 2017); doi: 10.1117/12.2280003

SPIE. Event: SPIE Optifab, 2017, Rochester, New York, United States 


\title{
Freeform Optics: Current Challenges for Future Serial Production
}

\author{
C. Schindler*, T. Köhler, E. Roth \\ Carl Zeiss Jena GmbH, Development Optical Manufacturing Technology, Carl-Zeiss Promenade 10, \\ 07745 Jena, Germany
}

\begin{abstract}
One of the major developments in optics industry recently is the commercial manufacturing of freeform surfaces for optical mid- and high performance systems. The loss of limitation on rotational symmetry enables completely new optical design solutions - but causes completely new challenges for the manufacturer too. Adapting the serial production from radialsymmetric to freeform optics cannot be done just by the extension of machine capabilities and software for every process step. New solutions for conventional optics productions or completely new process chains are necessary.
\end{abstract}

Keywords: optics manufacturing, freeform, optical systems, Alvarez, ultra-precision, computer generated hologram, laser based process

\section{INTRODUCTION}

As a worldwide operating company ZEISS did identify emerging applications that require high precision freeform surfaces. We classify them by market potential and required accuracy. One focus is on wavefront manipulators based on Alvarezplate type freeforms with high requirements that may be of interest for a great variety of applications. Due to the variable refractive power, the Alvarez-plates can be used as optics in diffraction limited universal wavefront manipulation. Their low temperature sensitivity makes them preferable over comparable solutions basing on other technologies like pressure or electro dependent fluid lenses or approaches based on liquid crystals.

The challenges for that type of freeform are a high diameter to thickness aspect ratio in combination with tight tolerances and demanding material properties. Tolerances span from form error over waviness to roughness limitations. Most common manufacturing techniques have to be improved to reach that goal in serial production. In addition a holistic approach for the whole process chain, including grinding, polishing, smoothing and figure correction, is necessary. We describe achievements and process improvements in ultra-precision grinding and deterministic polishing. Furthermore we discuss new tool approaches for large-aperture smoothing specifically built for mid-spatial frequency removal. Since each step includes tactile or interferometric testing also the measurements have to be adopted for efficient analysis. We conclude with a look on process chains apart from classical ones like laser based manufacturing and precision glass molding.

\section{FREEFORM SURFACES IN OPTICAL SYSTEMS}

Freeform surfaces do provide potential advantages for the design of optical systems ${ }^{1}$. They offer a maximum degree of freedom and flexibility to create novel design approaches and play a key role for the correction of optical systems, in particular for non-rotational symmetric systems, and the correction of asymmetrical wavefront errors. By placing freeform elements close to the field a flexible and efficient correction of $3^{\text {rd }}$-order errors like distortion can be achieved. With these qualities optical systems benefit towards better performances, more compact designs and lighter weight ${ }^{2}$.

*christian.schindler@ zeiss.com; phone +49 3641-642180; www.zeiss.com/carl-zeiss-jena

Optifab 2017, edited by Julie L. Bentley, Sebastian Stoebenau, Proc. of SPIE Vol. 10448, $1044802 \cdot$ (c) 2017 SPIE $\cdot$ CCC code: $0277-786 X / 17 / \$ 18 \cdot$ doi: $10.1117 / 12.2280003$ 
Unfortunately there are also demanding drawbacks for the use of freeforms in optical design and optimization. The description and optimization takes place in highly parameterized space, which lasts longer and in some instances does not lead to convergence of the design algorithms. Until today there is no conclusive aberration theory and so well-founded approaches for improvements are replaced by intuitive practices and do request highly educated staff. Furthermore the production and testing of freeform optics induces increased expenditures due to less or non-symmetric geometries and a high degree of individuality.

\subsection{Applications and market potential}

The desire to avoid self-shading effects in telescopes, head mounted - / head-up displays or in lithographic systems forces breaks in symmetry and does call for the application of freeform elements in Schiefspiegler systems. Monolithic optics with several freeform shaped surfaces are also entering the market for example as freeform prisms or monolithic telescopes. Oblique or rear projection systems with tilted object or image planes do benefit from freeform elements as well as highly asymmetric scan systems or anamorphic imaging applications. Additionally complex optical systems with decentered or tilted components like beam splitter plates, filter or cover glasses and tilted lenses are suitable for being improved with freeform surfaces. Another field of attraction are adaptive optics, in particular variable refractive optics for wavefront manipulation with moving freeform plates as shown in Figure 1.

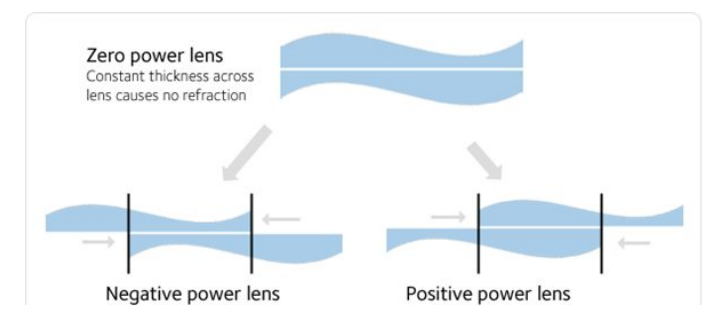

Figure 1 Alvarez-type freeform elements enable variable refractive optics

In comparison to pressure variable or electronical controlled fluid lenses or liquid crystal lenses the refractive power of Alvarez-lenses does not vary under temperature influence, does not degenerate over time and allows universal wavefront manipulation with also high refractive power, because every optical glass can be used. A pair of adjustable Alvarez-type freeforms provides variable optical power to the system by lateral movement and does work diffraction limited. Although the technical potential of these Alvarez-type freeforms is evaluated as high, the manufacturing efforts and costs still lower the broad use in optical systems.

\subsection{Typical Specifications}

There are various challenges being responsible for the high manufacturing efforts. To avoid wavefront errors, the manipulator plates need to be assembled close to each other. Both parts need to be thin. Figure 2 shows a representative drawing extract with typical properties. They also lead to further claims concerning stability in manufacturing process by tensions-free clamping techniques or the application of less process forces in order not to move or bend the parts. This causes less process throughput and additional tight tolerances in the lateral position of the freeform surface to the outer geometry. Since the parts need to be adjusted in all six degrees of freedom, exact references within the parts are required too. Both, the position and the outer geometry, need to be accurate in less than $50 \mu \mathrm{m}$. 

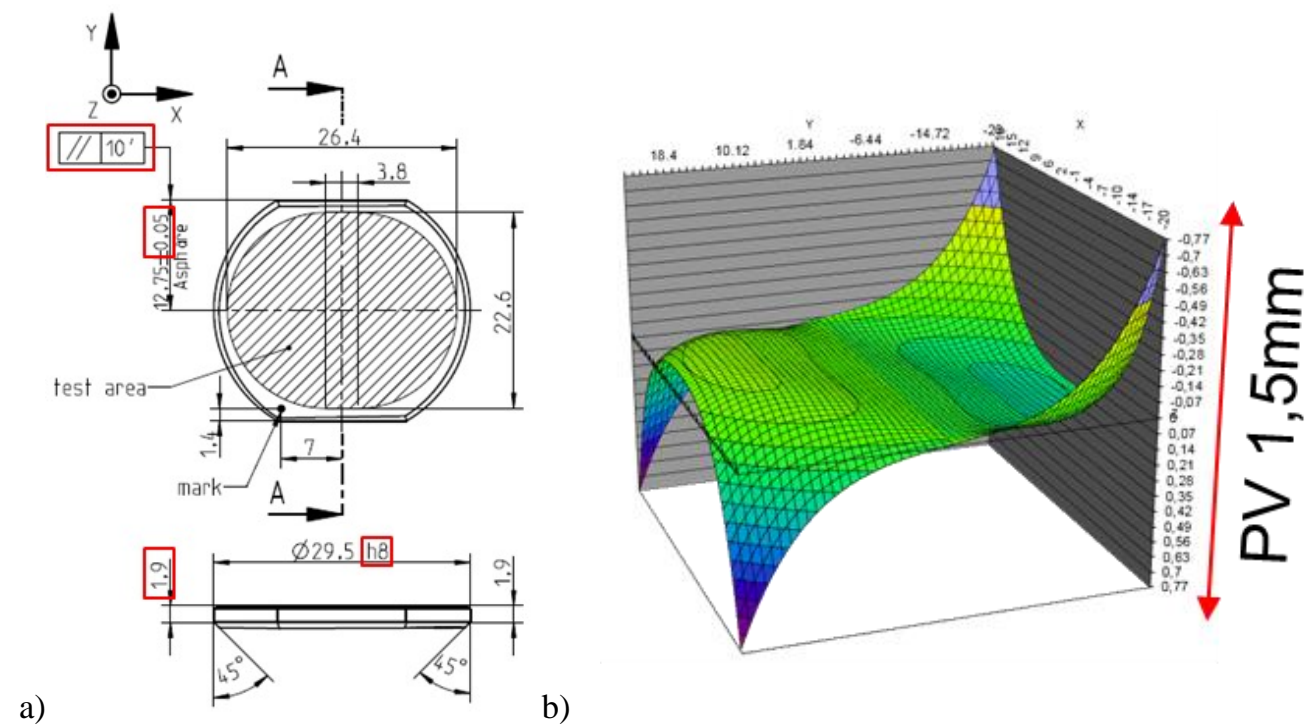

b)

Figure 2 a) representative sketch of freeform geometric tolerances; b) representative freeform surface with edge extrapolation

This is aggravated by small distances between clear aperture and the parts edges being forced by only little space provided by mechanical design. Since the applications are in high precision imaging, also tight tolerances for form, waviness and roughness need to be achieved. To ensure high contrast values, micro roughness needs to be less than $2 \mathrm{~nm}$ for a field of $(150 \times 150) \mu \mathrm{m}^{2}$ over the whole aperture. To separate deviations in form and waviness and their influences on the imaging quality, tolerances for the permitted surface deviation after deduction of adjustment degrees of freedom are split into spatial wavelengths ranging from 1 to $>16 \mathrm{~mm}$ with maximum rms ranging from 5 to $15 \mathrm{~nm}$, so less than $\lambda / 10$ (PV/WF). To make it even a bit more complicated, the refractive power of the glasses needs to be rather high, to keep the surface profiles as low as possible. Those are mostly uncommon glasses for manufacturing processes and do need specific process care and process know-how. Plastic optics do not yet provide the desired imaging quality. Typical surface amplitudes are $<2$ mm $\mathrm{PV}$ over the whole aperture as shown in Figure 2 and minimal local radii $>40 \mathrm{~mm}$.

\section{CLASSICAL PROCESS CHAIN}

Since there is a vast range of freeform optical imaging components, all claiming different requirements in terms of quality, price and quantity, also different manufacturing techniques come into play. Figure 3 gives an insight in those different requirements in terms of accuracy and amount per year by regarding the spectrum of mass optics towards high-end optics and their influence on price and manufacturing method.

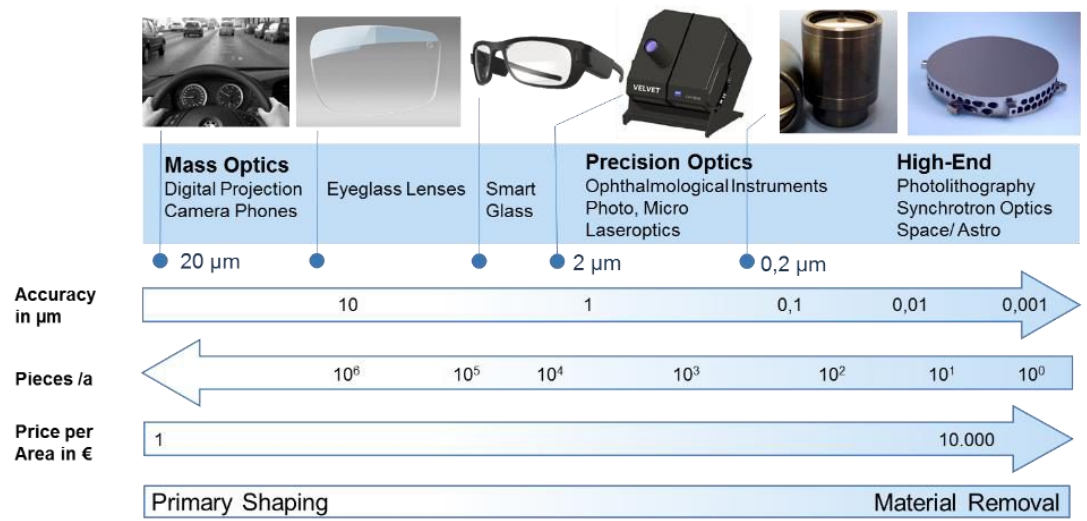

Figure 3 classification of optical components regarding quality, quantity, price and production methods 
The properties for those wavefront manipulating Alvarez-type freeforms are located in the field of precision optics in terms of quantity, but do still not yet take enough advantage from efficient manufacturing processes. So far a classical process chain based on high sophisticated grinding and polishing machinery, proprietary developments and well trained engineering staff is capable of supplying prototype-like parts in prototype-like quantities. A cost-effective process chain for serial production of several thousand parts per year for different types of freeform plates is still matter of ongoing technological development and improvements.

\subsection{Challenges and achievements}

Typical process flow for an optical system from idea to product is shown in Figure 4 and divided into three main parts. The classical process chain for optics manufacturing is part of the whole component manufacturing step and next to the optics design and prior to system integration. This consecutive process sequences do depend on each other and need to be coordinated.

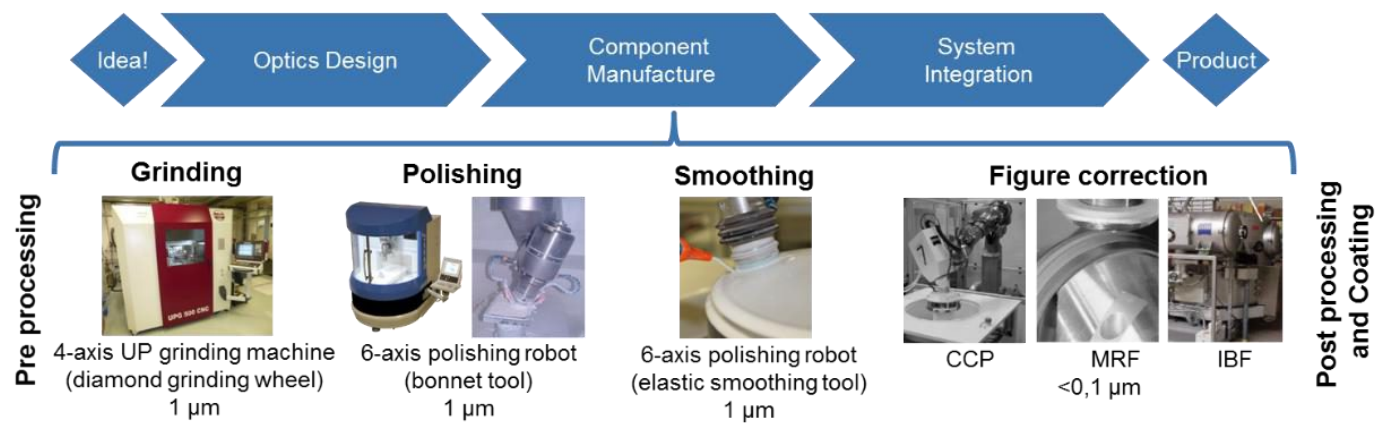

Figure 4 process sequences from idea to product with classical standard process chain for freeform manufacturing ${ }^{3}$

The classical freeform process chain is also derived from achievements in asphere manufacturing. After pre-processing and fixing the backside of the thin plates on a precision rod or zero point clamping system, a grinding process is applied, followed by polishing, smoothing and figure correction steps depending on final specs.

State of the art ultra-precise machining centers combined with in-house developments enable the production of Alvarezfreeform prototypes. UP-grinding machines with thermo-mechanical-stabilization are capable of shaping other freeforms in serial production down to $0.5 \mu \mathrm{m}$ accuracy with sub-surface damages in the range of $10-20 \mu \mathrm{m}$ depending on glass and tooling. Representative data is given in Figure 5. The residual form error after 2 to 5 iterative standard grinding steps with diamond grinding wheels is $>2 \mu \mathrm{m}$ with remaining mid-spatial frequency structures in the range of 0.5 to $5 \mathrm{~mm}$, which induce further iterative correction steps or do hardly fit to improvable wavelengths. In contrast there are no residual structures in the same range after one iterative loop of ultra-precision grinding and a remaining global form error is $<1$ $\mu \mathrm{m}$, which lead to a drop of machining, working and setup time.

\section{Status quo}

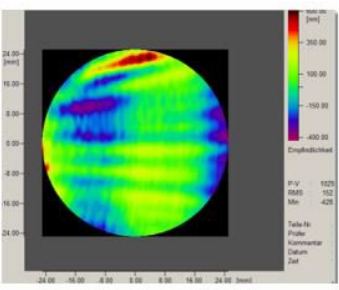

a)

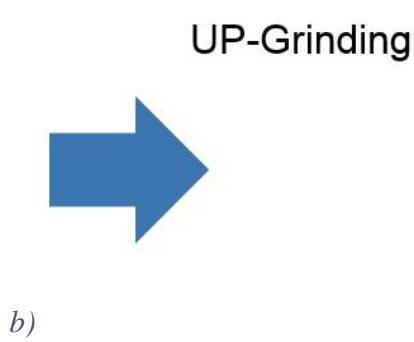

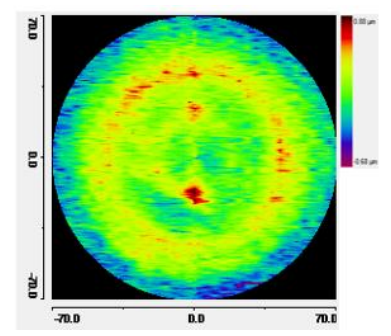

Figure 5 MSF-structures measured with CMM after freeform a) standard grinding process compared to b) UP-grinding

As mentioned before an additional advantage of UP-machining of glass is the possible reduction of sub-surface damage induced by the grinding process. Therefore a parameter specific optimization and evaluation of resulting surface quality is necessary. 15 to $20 \mu \mathrm{m}$ subsurface damage is good value for standard 4-axis grinding processes leading to more than 20 $\mu \mathrm{m}$ crucial pre-polishing material removal to secure passing visual inspection of scratch / dig. Due to precise, hydrostatic guides, dynamic drives and a rigid construction process improvements in microscale gets feasible. Freeform grinding with 
less than $15 \mu \mathrm{m}$ can be achieved and enables the reduction of necessary pre-polish removal height and as a result less effort for corrective iterations. Modified tooling and research in grinding theory ${ }^{4-6}$ allow additional reduction of sub-surface damage down to $<10 \mu \mathrm{m}$. Figure 6 gives an indication by microscopic pictures of ground surfaces for the transition from brittle to ductile grinding for high-index glasses on commercial UP-machinery with modified tooling and process parameter like infeed or cutting speed. This transition seems to be attractive for productive grinding but still suffers from tool wear and workpiece preparation.

a)
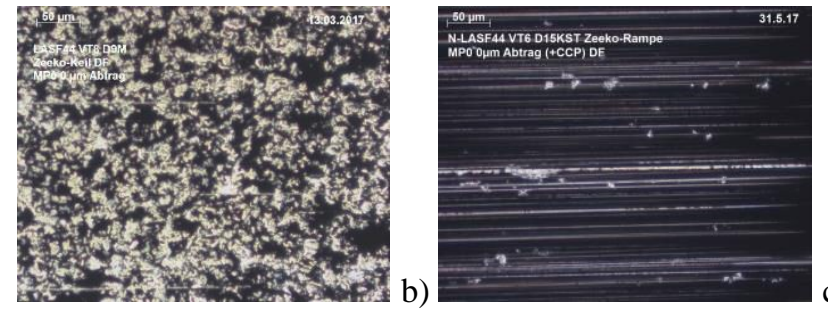

Figure 6 microscopic evaluation of different grinding modes a) brittle b) mixed c) ductile

The pre-polish process based on bonnet polishing is driven by the wish to predict local material removal by taking local radii and pressure changes into account. Therefor a GPU-based simulation model for the polishing process is implemented in the post-processing infrastructure. After modelling a specific tool function, its structure and form with finite element methods, a calculation of the localized pressure distribution in the contact zones between the tool and the freeformed workpiece surface is possible as seen in Figure 7 a) is performed. By adapting Preston and other polishing hypotheses a localized removal rate map and based on this a global removal profile are calculated and verified with experimental data. This model suites to optimize polishing and correction processes regarding process parameter, tool concepts and surfaces towards a deterministic, predictable and cost-effective polishing material removal for freeform elements.

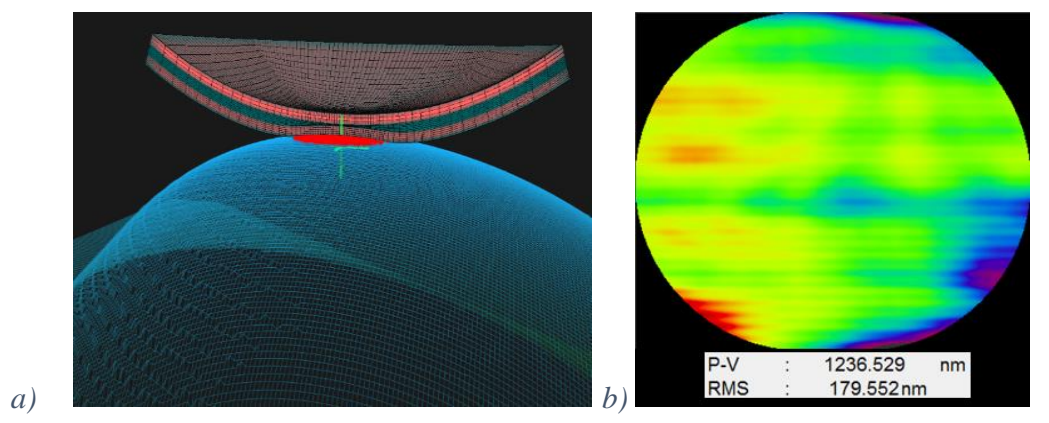

Figure 7 a) FEM tool modelling and calculation of localized removal rates on freeform surface by applying pre-calculated pressure distribution and polishing theories b) interferometric measurement of an early stage pre-polished substrate with MSF-structures

The required optical shape is calculated and designed mainly close to the clear aperture. The outer area has often no optical functions, is not determined and does often not even exist after edging to the final part size. But to polish and correct optical surfaces the applied tools need to overrun the edges depending on tool-size and process parameter. For an adequate polishing result steady edge extensions need to be extrapolated and added to the freeform surface without generating dynamic issues like jerks and jumps in acceleration, functional deviation or critical radii.

The point contact of the grinding wheel causes high frequent structures which can be passively smoothed within the subsequent polishing steps. Low frequent structures can be compensated by local correction. But the necessary removal of more than $20 \mu \mathrm{m}$ by pre-polishing and a first correction step results in further mid-spatial structures in the range of 0.5 to $2 \mathrm{~mm}$ and form errors of $<1.5 \mu \mathrm{m}$ PV as displayed in Figure $7 \mathrm{~b}$ ). Those structures need to be addressed by further correction effort by smoothing and figure correction. The drawback of these approaches comes with additional loops to correct form deviations added by the tools. This means an increase of internal loops and as follows an increase of manufacturing time and consequential costs. To correct MSF on freeforms, processing methods with smooth, elastic and adaptive tooling are essential. Therefore different approaches for flexible, large aperture tool setups for the removal of MSF-errors are under development. A composition of tool rigidity, the flexibility of pad materials and the calculation of 
tool paths needs to be optimized towards selective smoothing of MSF-structures. A frequency selective smoothing effect for a test pattern composed of wide spatial frequency disturbance as seen in Figure 8 is realized for critical wavelengths of $1-5 \mathrm{~mm}$ with a decrease from $25 \mathrm{~nm}$ down to $<5 \mathrm{~nm}$ in spatial rms.

a)

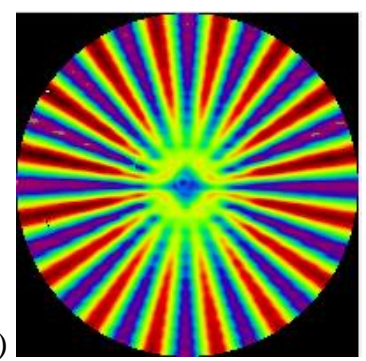

b)

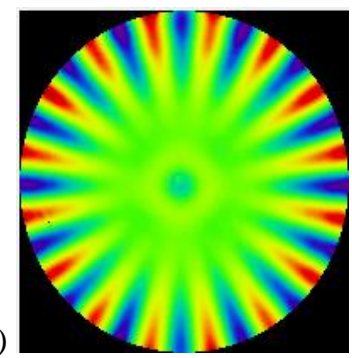

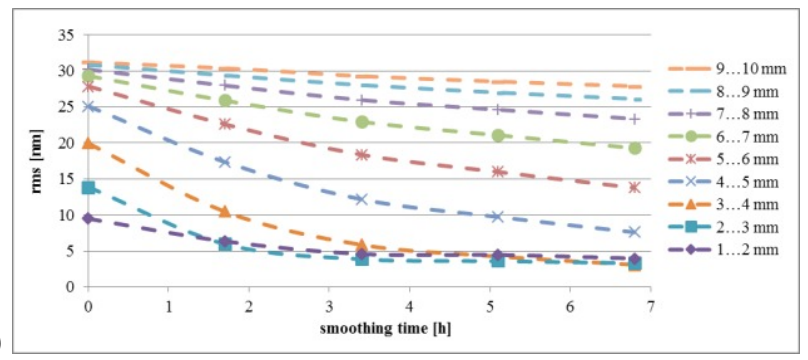

c)
Figure 8 interferometric measurements of a) test pattern and b) test pattern after selective smoothing and c) results after spatial frequency analysis

To correct further non-rotationally symmetric deviations, to achieve form accuracies $<0.1 \mu \mathrm{m}$ and to ensure tight micro roughness requirements, processes like MRF (magneto-rheological finishing) get finally applied. The achievable accuracy is practically limited by the measuring accuracy.

Furthermore a few comments on materials which do play a big role but being not addressed adequate in this explanations on freeform process chain. In particular soft and chemically unstable glass sorts may require special process treatment and additional development, which lead to higher costs. The optimal result concerning process costs and system performance depends on the material choice and a close cooperation between optical designer and manufacturer.

\section{ALTERNATIVE PROCESS CHAINS}

\subsection{Laser-based process chains}

Beside the classical process steps, laser based process chains or single process steps show advantages for optics manufacturing. The achievements over the last years are continuing in fields of ultrashort pulsed (USP) lasers and their application and widen the landscape of alternative technologies for optical component manufacturing and system integration. There are many potential USP-laser based processes in the long-term forecast: Athermal ablation for 3Dmaterial removal ${ }^{7-9}$ or local polishing ${ }^{10-13}$ by selective thermal interaction are two promising technologies, which combined in one machine could disrupt optics manufacturing. Other approaches like edging by ablation or by filament generation up to several millimeter thick glasses ${ }^{14}$, direct laser micro- or nanostructuring ${ }^{15-16}$, selective laser etching for micromachining 3D-parts ${ }^{17-18}$ or additive manufacturing techniques like two-photon polymerization for structured or printed optics ${ }^{19}$ are already applied in industrial environment. USP-laser bonding ${ }^{20-22}$ or in-volume marking ${ }^{23}$ do provide new optical features and benefits for systems integration / alignment.

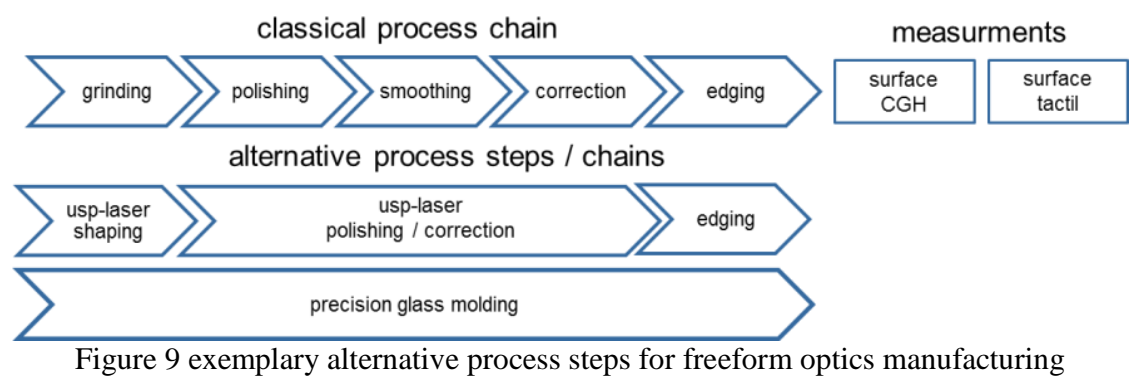

The USP-laser based ablation seems to be attractive for shaping freeform surfaces in a process chain like it is displayed in Figure 9. Processes such as grinding are limited in geometric diversity due to regiments in minimal tool sizes ${ }^{3}$. Machine builders build stiff and high precision and though cost-intensive machining centers to follow trends towards reliable ultra- 
precision grinding for serial production. As laser source manufactures came up with stable und high output power ultrashort pulsed lasers, contact- and wearfree as well as clean industrial machining of every material became a focus of broad attention. Sharp focusing of ultrashort laser pulses leads to very high intensities which enables nonlinear multiphoton absorption and plasma interaction no matter which material is irradiated. As consequence of physical processes matter gets ablated in the micrometer range by only very low thermal influence on material properties ${ }^{24}$. A constant material removal as well as the possibility of macroscopic glass ablation for optics manufacturing is possible ${ }^{25-29}$.

Primary laser parameter like pulse energy or fluence, wavelength as well as the applied pulse length and also geometric parameter like line or pulse overlap as well as material and environmental conditions do have to play a significant effect on the target figures roughness, induced sub-surface damage, form deviation and possible induced stress birefringence. After a certain amount of overscans, ablation regime runs into roughness saturation and constant ablation depths. With a so called multipass ablation process characteristic surface roughness rms $<1 \mu \mathrm{m}$, ablation depths $>0.1 \mu \mathrm{m}$ per overscan (surface passes), form deviations $<5 \mu \mathrm{m}$ and sub-surface damages of less than $10 \mu \mathrm{m}$ are attainable as exemplarily shown for fs- and ps-laser treated fused silica surfaces in Figure 10.

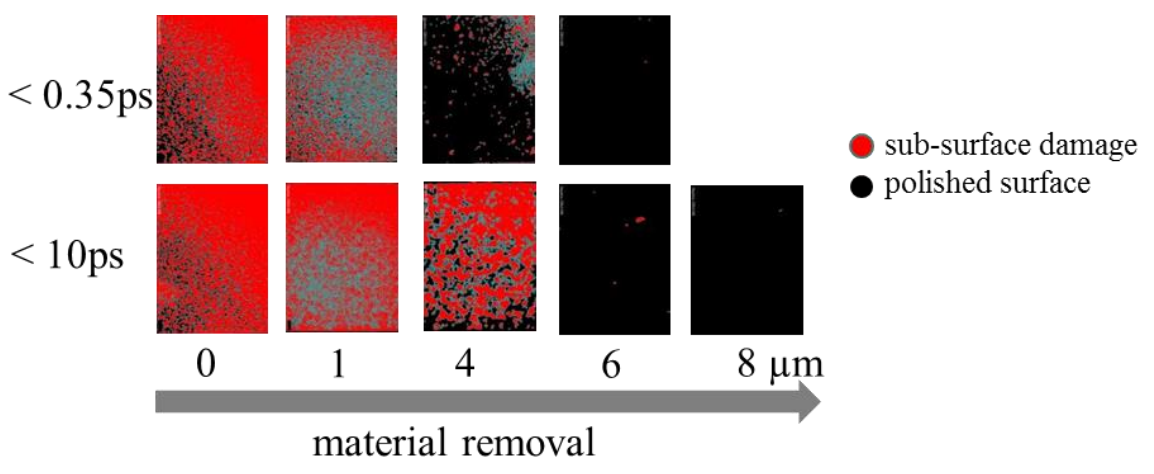

Figure 10 stepwise polishing of fs-/ ps-laser treated fused silica samples for sub-surface damage analysis ${ }^{29}$

\subsection{Precision glass molding}

Glass molding is an attractive method for mid- and high-volume manufacturing of spherical, aspherical as well as freeform optical elements. The whole classical process chain (grinding, polishing and correction steps) can be substituted and shortened as Figure 10 shows. Depending on desired quality two process regimes, non-isothermal and isothermal molding are available. First being applicable for high quantities, simple glasses but complex shapes, is limited to illumination optics due to temperature differences in process flow and thus less form accurate. Second regime (aka: precision glass molding) is suitable for middle quantities, delivers qualities for photo lenses, laser applications, micro- and IR-optics made from special low- $\mathrm{T}_{\mathrm{g}}$ glasses. In a thermally controlled regime the glass-preform gets pressed into the preheated tool and then cooled according to predetermined cooling curves. A multistage tool and shrinkage optimization process in combination with finite element process modelling is essential to achieve qualities in form accuracies $<1 \mu \mathrm{m}$ and roughness $<3 \mathrm{~nm}$ for aspherical and freeform surfaces. Due to long contact times and high temperatures between $500-700{ }^{\circ} \mathrm{C}$, the life cycle times of the tungsten carbide tools need to be extended by sputtering bonding and separating layers on the tool shapes and a cleanroom environment. Ultra-precision manufacturing machines, like UP-grinders, are necessary for the tool making processes. The high effort and preliminary development, put into several months lasting prototyping phases, can only be justified with quantities in the middle range starting from several 100 replicates of one tool geometry ${ }^{30-31}$. Actual subject for applied research, in the fields of process management, modelling and feedback into optics design, is the process-related drop and gradual change of refractive index in the range of $10^{-3}-10^{-4}$, the residual stress birefringence after molding the glass as well as the tough aspect ratio of the desired freeform plates. With positive achievements regarding these topics, sub- $\mu \mathrm{m}$ form errors seem to be likely achievable.

\section{MEASUREMENT TECHNIQUES}

As mentioned before, polishing non-rotationally symmetric freeform elements is still challenging and one big spot needs to be put on accurately measuring the surfaces shape. There are not many options to determine a polished freeform surfaces 
shape in the range of typical optical specifications. State of the art coordinate measuring machines used in serial production environment as seen in Figure 11 a) do provide accurate form measurements of $<1 \mu \mathrm{m}$ for form shaping processes. There are techniques to obtain even more precise values for corrections steps, but do also mean higher effort regarding climate stability, fiducials and highly trained staff in a prototyping process environment. Furthermore interferometric measurements based on computer generated holograms do provide appropriate data for freeform finishing and figure correction. Therefore the challenges are in adequate clamping and simplified alignment and measurement routines to ensure quick and distortion-free evaluation of form accuracy.
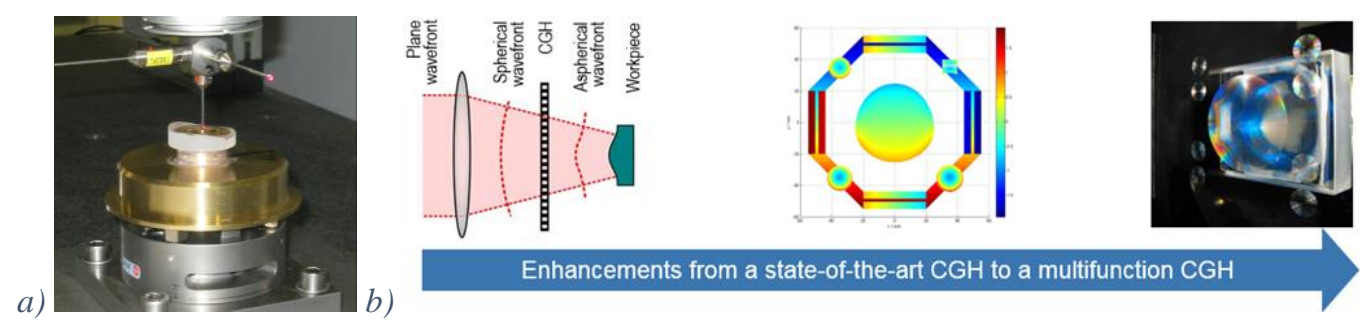

Figure 11 measurement techniques in freeform production processes: a) tactile coordinate measuring machine b) adapting state of the art aspheric measurement technology for multifunctional CGH technology

To be able to achieve those targets in serial production in a cost-effective manner, setup and measuring routines and durations need to be simplified and reduced to transfer the whole measurement from engineering to production level. Figure $11 \mathrm{~b}$ ) gives an idea of how state of the art CGH technology for asphere manufacturing is enhanced for freeform measurements. With the integration of additional alignment marks and the simulation of stray light and disturbing reflexes multifunctional computer generated holograms enable fast and reproducible alignment in six degrees of freedom and safe precious time. Future work should be performed in CGH-calibration and reduction of measurement uncertainty.

\section{CONCLUSION}

Freeforms show significant trends in academic and patent publications. There are lots of potential applications in the fields of imaging optics. For mass optics with moderate requirements in accuracy, freeforms are already widely used. For lots of high-end applications, freeform optics provide key functionality. The design optimization and the production as well as the testing of freeform optics is associated with increased efforts and not yet fully developed. Applicative advances by the use of freeform optics must be able to justify the increased efforts, which mainly lowers freeform usage. In particular, when freeform optics could substitute established technologies, further reduction of costs in production, testing and assembly of freeform optics are essential for a wider distribution. Therefor the next major challenge is the transfer from a prototype-like process towards cost-effective serial production. Referring to this, design to manufacture approaches are the starting point for system devolvement und engineering aiming on transparent und reproducible manufacturing steps. To do so a holistic view on process chains is necessary. The classical chain requires high form accuracy and low SSD grinding, FEM-based deterministic polishing, smoothing techniques for controlled MSF-reduction and advanced tactile and CGH metrology. Additionally alternative process chains like laser- or plasma-based and precision glass molding contain various disruptive potential.

\section{REFERENCES}

[1] T. Köhler, C. Schindler, E. Roth, "Mastering the Art of Freeform Optics Manufacturing", OptoNet Workshop: Ultra Precision Manufacturing of Aspheres and Freeforms", Jena, 2016

[2] N. Kerwien, "Der Preis der Freiheit: Fluch und Segen von Freiformen in abbildenden Systemen", OptecNetJahrestagung, Mainz, 2017

[3] R. Liebold, S. Frank, “Advancing freeform manufacturing @ ZEISS”, $3^{\text {rd }}$ European Seminar on Precision Optics Manufacturing, Teisnach, 2016 
[4] P. Simon, A. Beaucamp, P. Charlton, "Brittle-Ductile Transition in Shape Adaptive Grinding (SAG)", Frontiers in Optics, 2016

[5] A. Beaucamp, Y. Yoshiharu, P. Phillip, «Process mechanism in shape adaptive grinding (SAG)", CIRP Annals - Manufacturing Technology. 64, 2015

[6] F. Klocke, „Fertigungsverfahren Schleifen, Honen, Läppen”, Springer Verlag Berlin, Aachen. 2005

[7] C. Schindler, M. Friedrich, J. Bliedtner, "Analysis of Process Parameter for the Ablation of Optical Glasses with Femto- and Picosecond Laserpulses", Proc. SPIE. 9736, Laser-based Micro- and Nanoprocessing X, San Francisco, 2016.

[8] C. Schindler, et al, "Controlled USP laser ablation strategies for shaping optics", Proc. SPIE. 8428, Micro-Optics, Brüssel, 2012

[9] H., Sebastian: Abtragprozesse und Prozesskette zur laserbasierten Fertigung optischer Elemente aus Quarzglas. Shaker Verlag, Dissertation, 2014

[10] C. Schindler, J. Bliedtner, „Verfahrensentwicklung für den Freiformabtrag an präzisionsoptischen Bauteilen“, OptoNet Workshop: Präzisionsbearbeitung mit ultrakurzen Laserimpulsen, Jena, 2017

[11] J. Qiao, L.L. Taylor, J. Qiao, "Optics polishing using ultrafast laser radiation", $2^{\text {nd }}$ Conference on Laser Polishing, Aachen, 2016

[12] L.L. Taylor, J. Qiao, J. Qiao, “Advanced optic fabrication using ultrafast laser radiation”, Frontiers in Ultrafast Optics: Biomedical, Scientific and Industrial Applications XVI, San Francisco, 2016

[13] A. Gillner, C. Kalupka, P. Gretzki, U. Thombansen, "Process analytics of laser ablation processes", International Laser Technology Congress, Aachen, 2016

[14]D. Esser, S. Rezaei, J. Li, P. R. Herman, J. Gottmann, "Time dynamics of burst-train filamentation assisted femtosecond laser machining in glasses", Optics Express, 19(25), 25632-25642, 2011

[15] S. Steenhusen, F. Burmeister, H.C. Eckstein, R. Houbertz, "Two-photon polymerization of hybrid polymers for applications in micro-optics", Laser 3D Manufacturing, Proc. of SPIE 9353, San Francisco, 2015

[16] A. Brahm, S. Döring, A. Wilms, G. Notni, S. Nolte, and A. Tünnermann, "Laser-generated broadband antireflection structures for freeform silicon lenses at terahertz frequencies", Applied Optics Vol. 53, Issue 13, pp. 2886-2891, 2014

[17] D. Schaefer, J. Gottmann, "High speed micro scanner for 3D in-volume laser micro processing”, Proc. of SPIE: 8608,2013

[18] M. Beresna, M. Gecevicius, P. Kazansky, "Polarization sensitive elements fabricated by femtosecond laser nanostructuring of glass", Optical Society of America, 2011

[19] T. Gissibl, S. Thiele, A. Herkommer, H. Giessen, "Sub-micrometre accurate free-form optics by threedimensional printing on single-mode fibres", Nature Communications 7, 11763, 2016

[20] K. Cveček, „Einfluss der Wellenlänge auf das UKP-Schweißen“, Workshop: Laserbearbeitung von Glaswerkstoffen, Hannover, 2016

[21] S. Richter, S. Döring, A. Tünnermann, S. Nolte, "Bonding of glass with femtosecond laser pulses at high repetition rates", Appl. Phys. A-Mater. Sci. Process. 103 (2), 257-261 (2011)

[22]E. Kaiser, A. Killi, A. Budnicki, S. Pricking, M. Kumkar, "Welding of fused silica with femto second lasers enables new design options", LANE2016 - $9^{\text {th }}$ International Conference \& Exhibition on Photonic Technologies, Erlangen, 2016

[23]D. Richter, C. Voigtlaender, R. G. Kraemer, J. U. Thomas, A. Tünnermann, S. Nolte, "Discrete nonplanar reflections from an ultrashort pulse written volume Bragg grating," Opt. Lett. 40 (12), 2766-2769, 2015

[24]B. Jaeggi et al, "Influence of pulse duration in the ps-regime on the ablation efficiency of metals", Physics Procedia, 2011

[25] S. Wächter et al, "Investigation in structuring glass with ultra short pulsed laser ablation, International Laser and Coating Symposium", Dresden, 2014

[26] V. Giggel, "Process chain for ultra precise freeform optic components, OptoNet Workshop: Ultra Precision Manufacturing of Aspheres and Freeforms", Jena, 2010

[27] C. Schindler, J. Giesecke, J. Bliedtner, "Bestimmung von Abtragsschwellwerten und Tiefenabtrag von optischen Gläsern mittels UKP-Laserstrahlung", 13. Nachwuchswissenschaftler-Konferenz, Görlitz, 2012

[28] M. Sun et al, "Numerical analysis of laser ablation and damage in glass with picosecond laser pulses", Optics Express 7859, Vol.21, OSA, 2013

[29] H. Scheibe, C. Schindler, R. Theska, Technologies for cost-effective manufacturing of precision aspheres and freeforms", $59^{\text {th }}$ Ilmenau Scientific Colloquium, Ilmenau, 2017 
[30] J. Staasmeyer, H. Kreilkamp, O. Dambon, F. Klocke, "Precision glass molding: cost efficient production of glassoptics with spectral range from $180 \mathrm{~nm}$ ultraviolet to $13 \mu \mathrm{m}$ thermal infrared", Proc. Vol. 10009, $3^{\text {rd }}$ European Seminar on Precision Optics Manufacturing, 2016

[31] A. Symmons, J. Huddleston, D. Knowles, "Design for Manufacturability and Optical Performance Trade-offs using Precision Glass Molded Aspheric Lenses", Proc. of SPIE Vol. 9949, 2016 